\title{
An Experimental Study on the Effect of Pyrimethamine-Loaded Niosomes in the Treatment of Acute Toxoplasmosis
}

\author{
Basma M. El-Mansory ${ }^{1}$ *, Samy I. El-Kowrany ${ }^{1}$, Sirria M. El-Marhoumy ${ }^{1}$, \\ Kholoud A. El-Nouby ${ }^{1}$, Mona A. Abd Elazeem ${ }^{2}$ and Gamal M. El Maghraby ${ }^{3}$
}

${ }^{1}$ Department of Medical Parasitology, Faculty of Medicine, Tanta University, Tanta, Egypt

${ }^{2}$ Department of Pathology, Faculty of Medicine, Tanta University, Tanta, Egypt

${ }^{3}$ Department of Pharmaceutical Technology, Faculty of Pharmacy,

Tanta University, Tanta, Egypt

*Corresponding author

\section{A B S T R A C T}

\begin{tabular}{|c|}
\hline Keywords \\
\hline $\begin{array}{l}\text { Toxoplasma gondii. } \\
\text { Pyrimethamine. } \\
\text { Niosomes. } \\
\text { Nanostructures }\end{array}$ \\
\hline Article Info \\
\hline $\begin{array}{l}\text { Accepted: } \\
\text { 07 November } 2019 \\
\text { Available Online: } \\
10 \text { December } 2019\end{array}$ \\
\hline
\end{tabular}

Toxoplasma gondii infection has a worldwide distribution. Pyrimethamine (PYR) is the most effective drug for treatment of toxoplasmosis. Unfortunately, it has low oral bioavailability which requires an increase in the dose that results in increased its side effects. Nanostructures showed promising potential to overcome this problem. This study aimed to evaluate the effect of intraperitoneal injection (IP) of PYR-loaded niosomes compared to PYR in the treatment of acute toxoplasmosis in experimentally infected mice. The study employed 240 mice that were divided into groups. Group I included Ia (20 uninfected untreated), Ib (20 infected untreated), Ic (non-infected and injected with placebo niosomes) and Id (20 non-infected mice injected with dimethyl sulfoxide). Groups II and III (a \& b/each, 40 mice/each) were treated with PYR and PYR-loaded niosomes respectively in doses of 5 or $10 \mathrm{mg} / \mathrm{kg} /$ day for four successive days. Then all mice were sacrificed and their peritoneal fluids were examined by the scanning electron microscopy. Livers, spleens and brains were used for parasite count and for histopathological examination. This study showed that the niosomes improved the efficacy of PYR in the treatment of acute toxoplasmosis in mice. It was evidenced by increased the survival rate, decreased tachyzoites count, morphological changes of the tachyzoites and decreased inflammation. Niosomal PYR was effective at low dose with its efficacy being even greater than that of the solution even at high dose. It was concluded that PYR-niosomes formulation is a powerful alternative for reduction of PYR dose and its side effects.

\section{Introduction}

Toxoplasma gondii (T. gondii) infection has a worldwide distribution. Epidemiological surveys have suggested that up to one-third of the world's population are infected with this parasite (Munoz et al., 2011). Man acquires the infection through ingestion of tissue cysts in undercooked or raw meat or by accidental ingestion of mature oocysts in the 
contaminated food and drink. Congenital transmission is also another important route of infection that may lead to serious consequences. The infective stages of $T$. gondii include tachyzoite which is a rapidly dividing invasive stage, bradyzoite that is a slowly dividing in tissue cysts, and the sporozoite which is the environmental stage inside the oocyst. Tachyzoites are the dissemination forms that are able to invade nearly every nucleated cell in human body where they multiply in a parasitophorous vacuole (Robert-Gangneux and Dardé, 2012). These infective stages can invade the mucosa of the small intestine and multiply in the lymphoid macrophages in the lamina propria. They travel through lymphatics to invade the mesenteric lymph nodes where they proliferate before spreading by blood to all organs. In the immunocompetent hosts, the tachyzoites convert to chronic status forming bradyzoites which are encysted within the brain, eye and muscles. These cysts may remain dormant for life. When the immunity of the host decreases, the cysts rupture and the bradyzoites convert to the tachyzoites that invade new cells causing relapse (Hakeen 2010). This relapse can cause a life threatening systemic, ocular and most commonly neurological complications in these patients (Mordue et al., 2001; Pappas et al., 2009). Mortality due to toxoplasmic encephalitis (TE) in immunocompromised patients can reach $100 \%$ if treatment is delayed (Montoya et al., 2015).

Pyrimethamine is highly effective in treatment of TE especially when used in combination with sulfadiazine. However, the combination of PYR with sulfadiazine can cause bone marrow suppression, hematological toxicity and life-threatening skin allergic reactions. These side effects are mainly due to sulfonamides (Dhapte et al., 2013). Thus, administration of PYR as a single drug may help to prevent these sulfonamide-associated side effects. It is highly selective for the tachyzoite form of Toxoplasma gondii with efficient brain parenchyma penetration (Katlama et al., 1996; Leport et al., 1992). Unfortunately, PYR suffers from poor and variable bioavailability after oral administration. Also, it is subjected to extensive hepatic metabolism which limits the amount of drug reaching the systemic circulation. Only $10 \%$ to $25 \%$ of serum concentrations of the drug can reach the cerebrospinal fluid (Montoya et al., 2015). This requires an increase in the dose to achieve the therapeutic blood and CSF levels which results in increased its side effects. Moreover, PYR is subjected to development of resistance which is aggravated by increasing the dose. So the use of nanostructures may improve the bioavailability of PYR that can result in clinical benefits (Patravale et al., 2004; Rabinow, 2004). Nanoparticles are colloidal submicron particles ranging from $1 \mathrm{~nm}$ to 100 $\mathrm{nm}$ in size (Biswas et al., 2014). Nanocarriers are potential drug delivery vehicles that can take the ultradisperse drugs to the specific intracellular targets, which are surrounded by complex physiological barriers (Pohlmann et al., 2013). The problems of solid nanostructures include the difficulty of preparation and poor physical stability which leads to particle size enlargement (Naseri et al., 2015).

Niosomes are vesicular nanostructures that can encapsulate drugs irrespective to their physicochemical properties. They can be fabricated easily from non-ionic surfactants and cholesterol as the main components with minimal phospholipid being included in some cases. The properties can be further modified by manipulating the composition of niosomes. Peceol, a membrane fluidizing material has been added to niosomes to improve the oral bioavailability with the recorded positive results being explained on the base of 
enhanced membrane permeability and/or preferential lymphatic transport (Sultan et al., 2016, 2018; Zoghroban et al., 2019). These vesicles have been shown to enhance the bioavailability of many drugs with promising data being recorded against parasites like Shistosoma in vitro and in vivo (Zoghroban et al., 2019).

Accordingly, the objective of this work was to investigate the effect of niosomal encapsulation of pyrimethamine on its efficacy against acute $T$. gondii infection in mice.

\section{Materials and Methods}

\section{Parasite}

The RH virulent strain of Toxoplasma gondii was obtained from the Medical Parasitology Department, Faculty of Medicine, Alexandria University, Egypt. This was maintained at Medical Parasitology Department, Faculty of Medicine, Tanta University, Egypt by serial passages (at 3-4 days intervals) of tachyzoites intraperitoneally (IP) in Swiss albino mice (35 weeks old, $20 \mathrm{~g}$ weight).

The tachyzoites were collected from the peritoneal exudates of the mice on the $4^{\text {th }}$ day of infection, washed three times and diluted with phosphate buffer saline (PBS), pH 7.4. These were used for infecting the mice at a dose of $3.5 \times 10^{3}$ tachyzoites/mouse according to Saudi et al., (2008).

\section{Drugs}

Pyrimethamine powder (PYR) and Span 60 were obtained from Sigma-Aldrich, St. Louis, MO, USA. Peceol was obtained from Gattefosse, Saint- Priest Cedex, France. Cholesterol and ethanol were purchased from El-Nasr Pharmaceutical Chemicals Company, Cairo, Egypt.

\section{Preparation of the tested formulations}

Pyrimethamine solution $(1 \mathrm{mg} / \mathrm{ml})$ was prepared by dissolving the drug in dimethyl sulfoxide (DMSO) to produce $2 \mathrm{mg} / \mathrm{ml}$. This solution was diluted with equal volume of distilled water to prepare the required concentration.

Niosomes were prepared according to the composition presented in Table 1 (Sultan et al., 2016). Span 60, cholesterol, peceol and pyrimethamine were mixed before addition of ethanol. The mixture was heated on water bath to form clear dispersion. Water $(0.75 \mathrm{ml})$ was added with mixing in the water bath until clarity. The clear liquid was removed from the water bath and cooled while mixing to form proniosomal gel. The remaining amount of water was added with continuous mixing to produce niosomes which were left to swell and hydrate for an overnight. Niosomes were then subjected to bath sonication for 30 minutes.

\section{Experimental animals}

Two hundred and forty laboratory-bred male Swiss albino mice, aged 3-5 weeks and weighing 20-25 g were used. The mice were housed according to the guidelines of care and usage of animals for scientific purposes. Mice stool was examined microscopically to exclude the presence of parasites. This study was approved by the Ethics Committee of Tanta University, Egypt.

\section{Experimental groups}

The mice were divided into three main groups

\section{Group I (Control group)}

This group included 80 mice that were subdivided equally into four subgroups: 


\section{Subgroup Ia}

Subgroup Ia included 20 non-infected nontreated mice which were served as a control healthy group that were sacrificed at the beginning of the experiment for the comparative study.

\section{Subgroup Ib}

Subgroup Ib included 20 infected non-treated mice.

\section{Subgroup Ic}

Subgroup Ic included 20 non-infected mice that were injected intraperitoneally (IP) with $0.1 \mathrm{ml}$ of non-medicated niosomes for four successive days.

\section{Subgroup Id}

Subgroup Id included 20 non-infected mice that were injected intraperitoneally (IP) with $0.1 \mathrm{ml}$ of DMSO for four successive days.

\section{Group II}

This group included 80 experimentally infected mice that were subdivided equally into two subgroups. These subgroups were treated with pyrimethamine (PYR) alone in different doses according to Pissinate et al., (2014) as follow:

\section{Subgroup IIa}

Subgroup IIa included 40 mice which were injected IP with PYR alone in a dose of 5 $\mathrm{mg} / \mathrm{kg} / \mathrm{day}$.

\section{Subgroup IIb}

Subgroup IIb included 40 mice which were injected IP with PYR alone in a dose of 10 $\mathrm{mg} / \mathrm{kg} /$ day.

\section{Group III}

This group included 80 experimentally infected mice that were subdivided equally into two subgroups. These subgroups were treated with pyrimethamine-loaded niosmes (PYR-niosomes) in different doses according to Pissinate et al., (2014) as follow:

\section{Subgroup IIIa}

Subgroup IIIa included 40 mice which were injected IP with PYR-niosomes in a dose of 5 $\mathrm{mg} / \mathrm{kg} / \mathrm{day}$.

\section{Subgroup IIIb}

Subgroup IIIb included 40 mice which were injected IP with PYR-niosomes in a dose of 10 $\mathrm{mg} / \mathrm{kg} / \mathrm{day}$.

The treatment was initiated 24 hours postinfection in the studied groups and continued for four successive days according to Saudi $e t$ al., (2008). On the $5^{\text {th }}$ day post infection, all the mice of the studied groups were anesthetized, sacrificed and subjected to the followings:

\section{Parasitological evaluation}

\section{Survival rate estimation}

The survival rate was calculated in each group according to the following equation (Eissa $e t$ al., 2012)

$\frac{\text { Number of survived mice at the alcrifice time }}{\text { number of mice at the beginning of the experiment }} \times 100$

\section{Parasite load}

The mean parasitic count was estimated in the Giemsa stained impression smears made from the livers, spleens and brains of the mice using the oil immersion objectives $(\times 100)$ lens. The mean number of tachyzoites of ten different 
fields from each studied organ of each mouse was calculated then the mean number of each infected subgroup was determined (Thiptara $e t$ al., 2006).

\section{Morphological study}

The peritoneal fluids of the studied groups were examined by the scanning electron microscopy (SEM) for detection of the morphological changes of $T$. gondii tachyzoites collected on the 5 th day post infection from each group. The peritoneal fluids were washed twice with PBS, and then fixed in glutaraldehyde. The specimens were washed 3 times by flooding with large volumes of sterile distilled water then processed according to Klainer and Betsch (1970), and examined using a Jeol-JSM-25 SII scanning microscope.

\section{Histopathological study}

Specimens from the livers, spleens and brains of the mice were processed for histological examination and examined to assess the presence of inflammation and the parasite.

\section{Biochemical study}

Urea and liver enzymes; aspartate aminotransferase (AST) and alanine aminotransferase (ALT) levels were measured in the sera of the non infected control group Ic (injected IP with the non-medicated niosomes alone) and group Id (injected IP with DMSO) as compared to the healthy control group at the sacrifice time according to Sharma et al., (2003) and Paul et al., (2010).

\section{Ethics statement}

The study protocol was approved and conducted according to the guidelines of the Laboratory Animal Centre for Research Ethics Committee at Faculty of Medicine, Tanta University (code number: 31303/01/17).

\section{Statistical data analysis}

These data were analyzed by one-way ANOVA followed by Turkey's multiple comparison as a post hoc test to determine significance of differences between groups using Statistical Package for Social Sciences (SPSS) (SPSS Inc., Chicago, Illinois, USA), software for windows, version (20). The difference was considered statistically significant when $\mathrm{P}<0.05$ according to Leslie et al., (1991).

\section{Results and Discussion}

\section{Survival rate estimation}

The infected untreated group showed the lowest survival rate. Only $60 \%$ of the infected mice surviving on the $5^{\text {th }}$ day post infection. Treatment with unprocessed pyrimethamine at doses of 5 and $10 \mathrm{mg} / \mathrm{kg} /$ day increased the survival rate to $85 \%, 87.5 \%$ respectively. Treatment with noisome encapsulated drug at the same doses increased the survival rate to reach $90 \%$ and $95 \%$ respectively.

\section{Parasite load}

Figures 1-3 show representative light micrographs of the Giemsa-stained impression smears of liver, spleen and brain. The figures show the parasite load in these tissues before and after treatment with pyrimethamine or PYR-niosomes. The estimated numbers of the tachyzoites are presented in Table 2. There was a statistically significant reduction in the mean number of the Toxoplasma tachyzoites in the treated subgroups as compared to the infected control group in all studied organs.

Also significant decrease $(\mathrm{p}<0.05)$ was detected between the subgroups IIa and IIb and the subgroups IIIa and IIIb. Also the difference between IIIa and IIb was significant in all studied organs (Table 2 and Fig. 1, 2 and 3). 


\section{Morphological study}

Figure 4 shows scanning electron micrographs of the morphological changes of tachyzoites recovered from the peritoneal exudates before and after treatment with pyrimethamine solution or niosomes. The tachyzoites recovered from the untreated group were of typical crescent shape with smooth regular surface. Treatment with PYR solution resulted in deformation of the tachyzoites which were distended and showed irregular ridges, deep furrows and disorganized conoid. This effect increased by increasing the dose. Treatment with PYR-niosomes resulted in higher degree of deformation with the recovered tachyzoites showed further increase in the severity of the deformation (Fig. 4).

\section{Histopathological study}

Figures 5-7 shows haematoxylin and eosin stained sections of livers, spleens and brains tissues recovered from uninfected mice, infected mice and infected treated mice. The uninfected mice showed normal histological features of each organ. The infected untreated group was characterized by marked inflammatory changes in the liver showing marked infiltration of portal tracts by inflammatory cells in addition to hydropic degeneration and fatty changes of hepatocytes. This was associated with congestion of central veins. Pseudocysts were also seen in the liver tissue reflecting the existence of large number of tachyzoites. Treatment with PYR solution reduced the inflammatory changes with the liver tissue showing moderate infiltration of portal tracts by inflammatory cells and congestion of central veins. Increasing the dose to $10 \mathrm{mg} / \mathrm{kg}$ improved the picture which showed more reduction in these inflammatory changes. Treatment with PYR-niosomes resulted in further improvement of the histopathological features which showed mild infiltration of portal tracts by lymphocytes and mild congestion of the central vein. The efficacy was further fortified on using higher dose of PYR niosomes (Fig. 5).

Regarding spleen sections, the infected control group showed hyperplastic lymphoid follicles, dilated congested sinusoids and marked infiltration by mono and multinucleated giant cells. Also Toxoplasma pseudocysts could be seen in the tissue. Treatment with PYR solution reduced the lymphoid follicles hyperplasia and congestion of the sinusoids while with increasing the dose of PYR there was a reduction in these changes in addition to decrease of the giant cells. Administration of PYR-niosomes resulted in a reduction in the lymphoid follicles hyperplasia. The dilatation of the congested sinusoids and their infiltration with a few giant cells became less evident. The higher dose of PYR-niosmes resulted in further improvement in the degree of inflammation (Fig. 6).

Concerning brain sections, heavy inflammatory infiltrates and increased cellularity were observed in the infected untreated mice. The treatment of PYR decreased these inflammatory infiltrations in dose dependant manner while the use of PYRniosomes showed a mild degree of inflammation and the higher dose resulted in further reduction of the inflammatory infiltration (Fig. 7).

\section{Biochemical study}

Table 3 presents the biochemical levels of normal mice and those receiving placebo niosomes or DMSO. The results reveal no significant increase in the serum levels of urea and the liver enzymes (AST and ALT) in the after intraperitoneal administration of drug free niosomes or DMSO (Table 3).

The treatment of toxoplasmosis is considered a huge challenge as there is no effective and 
safe treatment up till now. The standard treatment is the combination of pyrimethamine (PYR) and sulfadiazine but this combined treatment is often associated with severe side effects which are intolerable by the patients (Anderson, 2005). This requires searching for and development of new drug candidates, a process which is very expensive and time consuming. Improvement of an existing drug is an alternative strategy with investigators concentrating on enhancing the bioavailability and tissue distribution of the target drugs. Colloidal nanostructures showed promising potential in this respect (Prieto et al., 2006). Niosomes are novel nanoscale drug carriers which have a high biological and physical stability that enable the delivery of the drug to its target site in a controlled manner (Mehta and Jindal 2014). Modulation of niosomal composition can tailor their characteristics with incorporation of peceol showing enhanced membrane permeability. Niosomes can travel through the lymphatic system before reaching the systemic circulation (Sultan et al., 2017). Accordingly, peceol containing niosomes were employed as nanocarrier for enhanced delivery of PYR against acute toxoplasmosis in mice.

The efficacy of treatment was assessed by monitoring the survival rate, the parasite load in the liver, spleen and brain. In addition, morphological changes in the tachyzoites, histopathological changes and immunological response were also investigated. With respect to the survival rate, the infected untreated group showed the lowest survival rate. This rapid death of mice could be explained by the rapid and aggressive dissemination of the Toxoplasma tachyzoites in all cells of the mice (Sibley et al., 2002). The survival rate was increased after treatment with PYR solution in a dose dependent manner. This increase can be attributed to the inhibitory effect of PYR on tachyzoite replication with incomplete cure being attributed to low bioavailability of the drug. The superiority of niosomal PYR over the drug solution can imply better bioavailability from niosomes.

Similarly, Pissinate et al., (2014) found that the lipid-core nanocapsules (LNC) loaded with PYR significantly improved the survival rate of the mice as compared to PYR alone. These results agree with that recorded in previous studies that proved that the use of nanosystems improved the efficacy of the antitoxoplasmic drugs and the survival rate in the treatment of acute toxoplasmosis in mice as Sordet et al., (1998), Schöler et al., (2001), Dunay et al., (2004) and Shubar et al., (2009 and 2011) and Anand et al., (2015).

Regarding the parasite load, it could detect the density of the infection in tissues (El-Temsahy et al., 2002). There was a rapid dissemination of the parasite to the liver, spleen and brain of the infected control subgroup. This finding was in agreement with the studies done by ElTemsahy et al., (2002), Sibley et al., (2002), Eissa et al., (2012) and El Temsahy et al., (2016). There was a highly statistically significant reduction in the mean count of Toxoplasma tachyzoites in the treated subgroups as compared to the infected control group. PYR-niosomes were more effective in reducing the parasite load in all studied organs in the low dose of $5 \mathrm{mg} / \mathrm{kg} /$ day than PYR alone in the higher dose. This result agrees with Anand et al., (2015) who found that the use of the encapsulated bovine lactoferrin protein nanocapsules led to reduction of the parasite load in the mice acutely infected with toxoplasmosis. 
Table.1 The composition of PYR-niosomes

\begin{tabular}{|c|c|}
\hline Material & Amount \\
\hline Span 60 & 0.6 gram $(\mathrm{g})$ \\
\hline Cholesterol & $0.15 \mathrm{~g}$ \\
\hline Peceol & $0.15 \mathrm{~g}$ \\
\hline Ethanol & $0.75 \mathrm{~g}$ \\
\hline Water to & $25 \mathrm{ml}$ \\
\hline Pyrimethamine & $0.025 \mathrm{~g}$ \\
\hline
\end{tabular}

Table.2 The mean count of Toxoplasma tachyzoites in the organs of the studied subgroups

\begin{tabular}{|c|c|c|c|c|c|c|}
\hline Organ & Subgroups & Ib $(n=12)$ & IIa $(n=34)$ & IIb $(n=35)$ & IIIa $(n=36)$ & IIIb $(n=38)$ \\
\hline \multirow[t]{5}{*}{ Liver } & Mean \pm SD & $7.9 \pm 1.43$ & $7.4 \pm 1.43$ & $6.1 \pm 0.65$ & $1.5 \pm 0.60$ & $1.0 \pm 0.48$ \\
\hline & P1 & & 0.079 & 0.001* & $0.001 *$ & $0.001 *$ \\
\hline & $\mathbf{P 2}$ & & & $0.001 *$ & $0.001 *$ & $0.001 *$ \\
\hline & P3 & & & & 0.001* & 0.001* \\
\hline & P4 & & & & & $0.012 *$ \\
\hline \multirow[t]{5}{*}{ Spleen } & Mean \pm SD & $4.3 \pm 0.76$ & $3.2 \pm 0.53$ & $2.2 \pm 0.91$ & $0.8 \pm 0.33$ & $0.5 \pm 0.26$ \\
\hline & P1 & & 0.001* & 0.001* & $0.001 *$ & $0.001 *$ \\
\hline & P2 & & & 0.001* & 0.001* & $0.001 *$ \\
\hline & P3 & & & & 0.001* & $0.001 *$ \\
\hline & P4 & & & & & $0.026 *$ \\
\hline \multirow[t]{5}{*}{ Brain } & Mean \pm SD & $2 \pm 0.43$ & $1.3 \pm 0.43$ & $1.0 \pm 0.66$ & $0.4 \pm 0.22$ & $0.2 \pm 0.18$ \\
\hline & P1 & & 0.001* & 0.001* & 0.001* & $0.001 *$ \\
\hline & $\mathbf{P 2}$ & & & $0.007 *$ & $0.001 *$ & $0.001 *$ \\
\hline & P3 & & & & 0.001* & 0.001* \\
\hline & P4 & & & & & 0.037* \\
\hline
\end{tabular}

*Significant $(\mathbf{p}<0.05)$

Ib: $T$. gondii infected untreated mice.

II: $T$. gondii infected mice treated IP with PYR alone in doses of $5 \mathrm{mg} / \mathrm{kg} / \mathrm{day}$ (IIa) or $10 \mathrm{mg} / \mathrm{kg} / \mathrm{day}$ (IIb).

III: $T$. gondii infected mice treated IP with PYR-niosomes in doses of $5 \mathrm{mg} / \mathrm{kg} / \mathrm{day}$ (IIIa) or $10 \mathrm{mg} / \mathrm{kg} / \mathrm{day}$ (IIIb).

P values:

P1: Comparison with Ib +ve control; P2: Comparison of IIa with IIb, IIIa and IIIb.

P3: Comparison of IIb with IIIa and IIIb; P4: Comparison of IIIa with IIIb.

Table.3 Urea and liver enzymes (AST and ALT) levels in the serum of the control subgroups

\begin{tabular}{|c|c|c|c|c|c|}
\hline Biochemical parameter & Ia $(\mathbf{n = 2 0})$ & Ic $(\mathbf{n = 2 0})$ & Id $(\mathbf{n = 2 0})$ & P 1 & P 2 \\
\hline Urea (mean \pm SD) & $27.65 \pm 1.35$ & $28.02 \pm 1.31$ & $28.47 \pm 1.65$ & 0.421 & 0.078 \\
\hline AST (mean \pm SD) & $75.70 \pm 18.47$ & $76.39 \pm 12.52$ & $80.48 \pm 10.49$ & 0.879 & 0.292 \\
\hline ALT (mean \pm SD) & $47.93 \pm 14.02$ & $50.76 \pm 10.24$ & $51.79 \pm 7.09$ & 0.411 & 0.264 \\
\hline
\end{tabular}

*Significant $(\mathbf{p}<0.05)$

Ia: non-infected untreated mice.

Ic: non-infected mice that were injected IP with the niosomes alone in a dose of $5 \mathrm{mg} / \mathrm{kg} / \mathrm{day}$.

Id: non-infected mice that were injected IP with DMSO in a dose of $5 \mathrm{mg} / \mathrm{kg} / \mathrm{day}$.

P values: P1: comparison of Ia with Ic; P2: comparison of Ia with Id. 
Fig.1 Giemsa stained liver impression smears of the mice of the studied subgroups (x1000) a $T$. gondii infected untreated mice (Ib). b T. gondii infected mice treated with PYR $5 \mathrm{mg} / \mathrm{kg} / \mathrm{day}$ (IIa). c T. gondii infected mice treated with PYR $10 \mathrm{mg} / \mathrm{kg} / \mathrm{day}$ (IIb). d T. gondii infected mice treated with PYR-niosomes $5 \mathrm{mg} / \mathrm{kg} /$ day (IIIa). e $T$. gondii infected mice treated with PYRniosomes $10 \mathrm{mg} / \mathrm{kg} /$ day (IIIb)
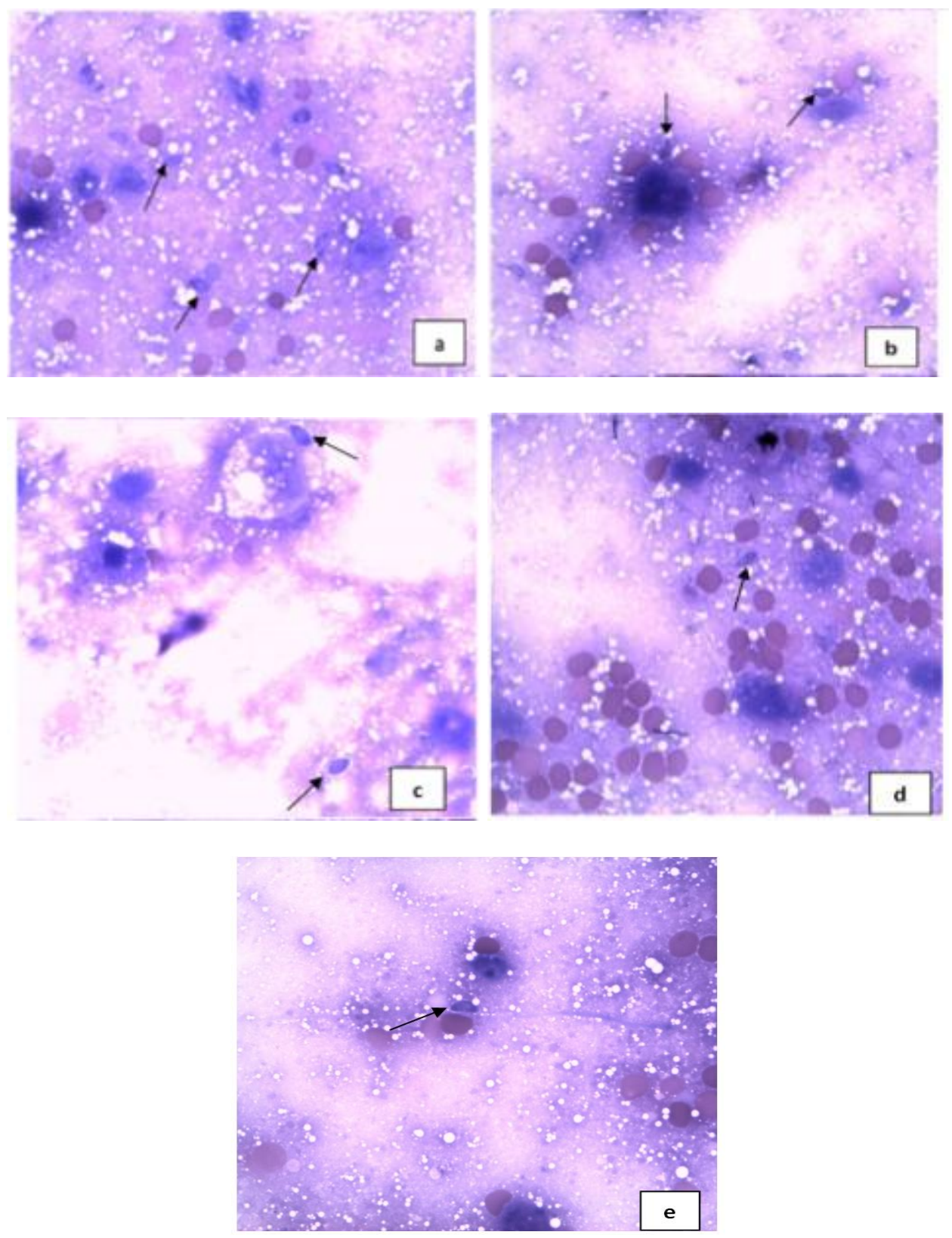
Fig.2 Giemsa stained spleen impression smears of the mice of the studied subgroups (x1000) a $T$. gondii infected untreated mice (Ib). b $T$. gondii infected mice treated with PYR $5 \mathrm{mg} / \mathrm{kg} / \mathrm{day}$ (IIa). c T. gondii infected mice treated with PYR $10 \mathrm{mg} / \mathrm{kg} / \mathrm{day}$ (IIb). d T. gondii infected mice treated with PYR-niosomes $5 \mathrm{mg} / \mathrm{kg} /$ day (IIIa). e $T$. gondii infected mice treated with PYRniosomes $10 \mathrm{mg} / \mathrm{kg} /$ day (IIIb)
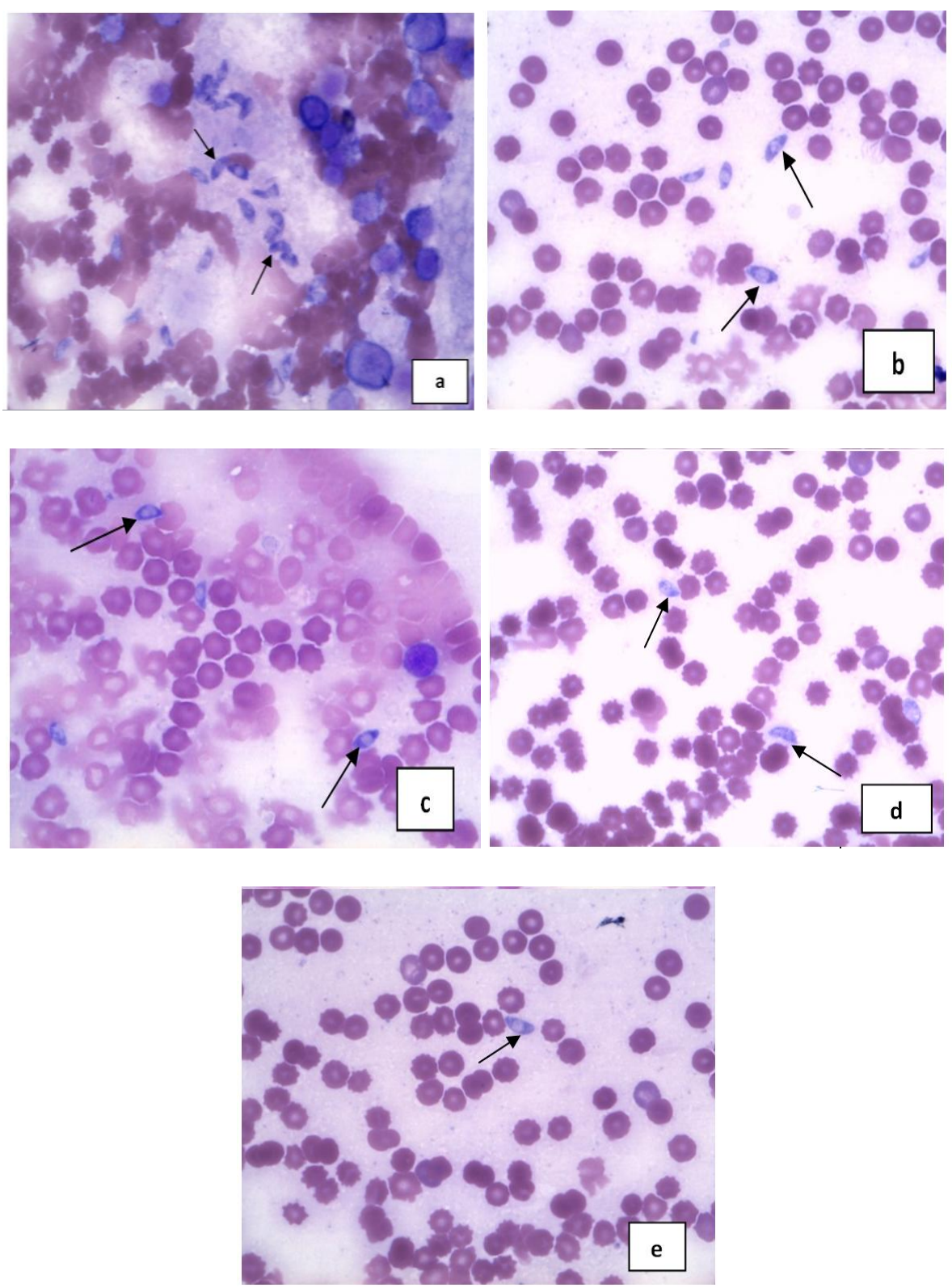
Fig.3 Giemsa stained brain impression smears of the mice of the studied subgroups (x1000) a $T$. gondii infected untreated mice (Ib). b T. gondii infected mice treated with PYR $5 \mathrm{mg} / \mathrm{kg} / \mathrm{day}$ (IIa). c T. gondii infected mice treated with PYR $10 \mathrm{mg} / \mathrm{kg} / \mathrm{day}$ (IIb). d T. gondii infected mice treated with PYR-niosomes $5 \mathrm{mg} / \mathrm{kg} /$ day (IIIa). e $T$. gondii infected mice treated with PYRniosomes $10 \mathrm{mg} / \mathrm{kg} /$ day (IIIb)
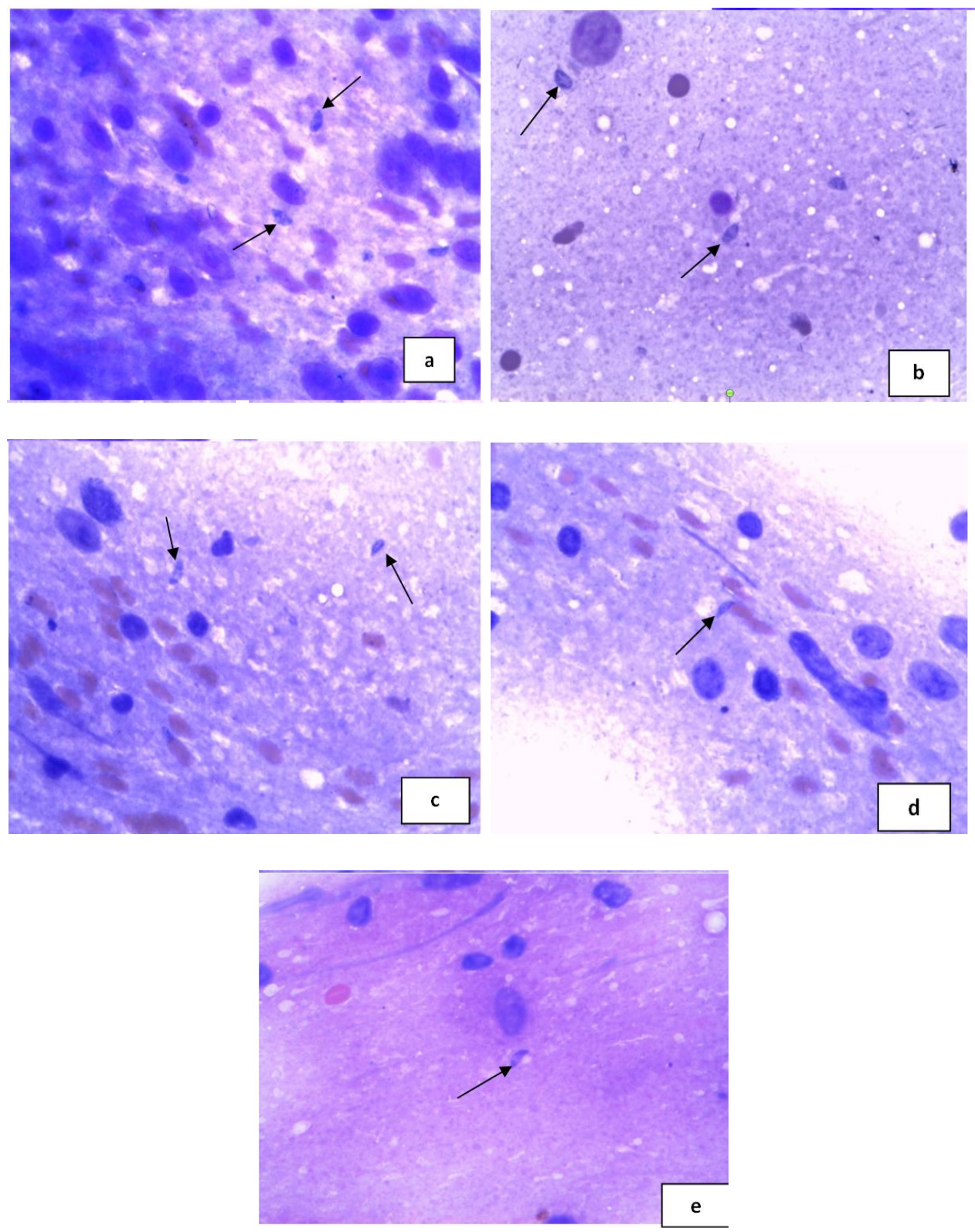
Fig.4 Toxoplasma gondii tachyzoite in the studied subgroups by SEM (x15, 000) a A SEM of $T$. gondii tachyzoite in the infected control group $\mathrm{Ib}$ showing the crescent shape with smooth regular surface and evident conoid (x15, 000). b A SEM of $T$. gondii tachyzoite in the group IIa showing irregular surface, some dimples and papules on its surface (arrows) with preservation of the crescent shape and the conoid $(\mathrm{x} 15,000)$. c A SEM of $T$. gondii tachyzoite in the group IIb showing multiple papules and dimples (arrows) with loss of the crescent shape and disorganized conoid (x15, 000). d A SEM of T. gondii tachyzoite in the group IIIa that appears elongated and more distended with multiple ridges and irregular papules (arrows) on the surface (x15, 000). e A SEM of $T$. gondii tachyzoite in the group IIIb showing severe distension and deformity in its shape in form of large irregular ridges and deep furrows (arrows) with disorganized conoid (x15, 000)
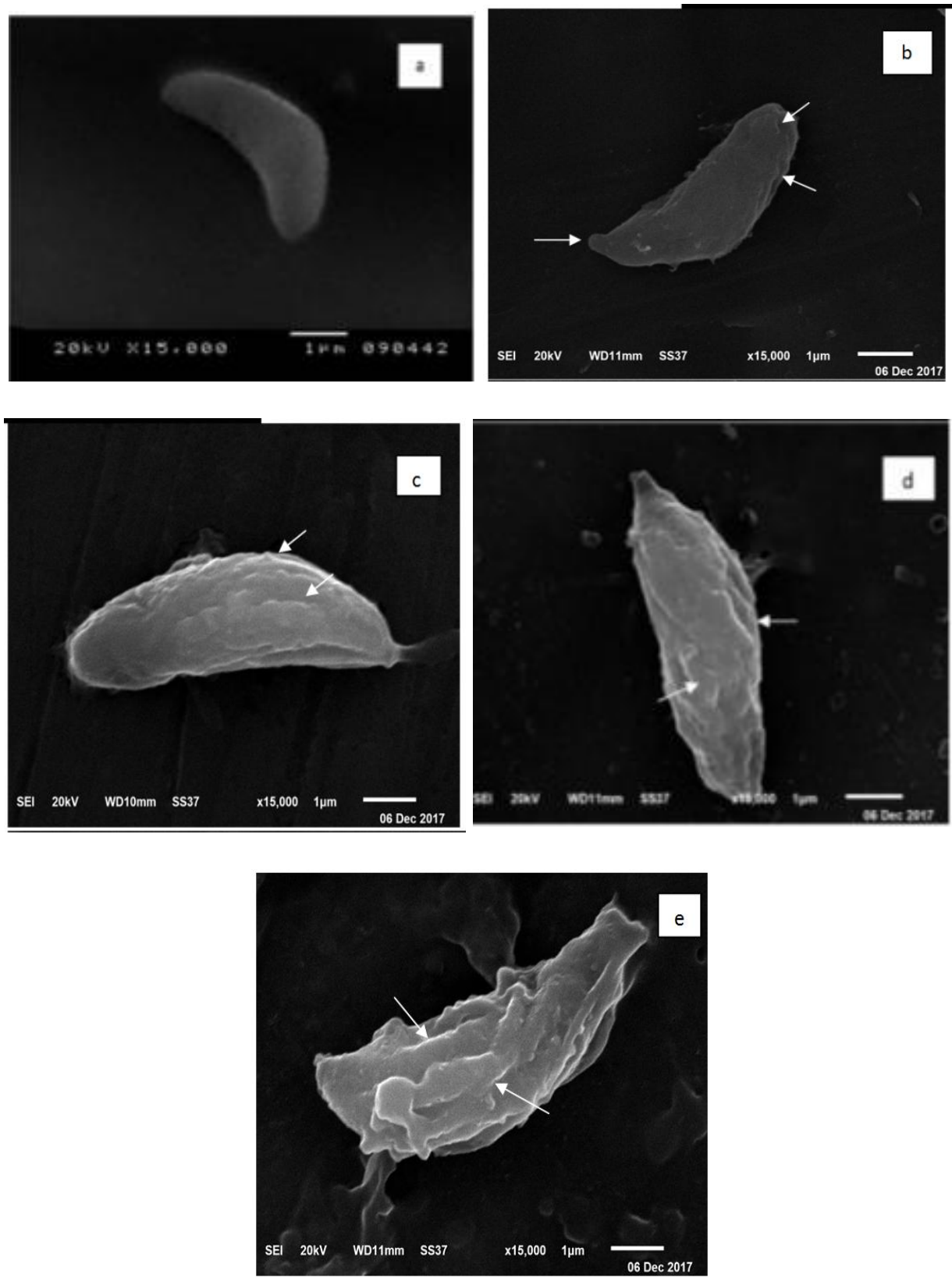
Fig.5 Liver sections of the studied subgroups. a A liver section of uninfected untreated control subgroup Ia showing features of a normal hepatic architecture with normal hepatocytes $(\mathrm{H})$ and central veins (CV) (H\&E x200). b. A liver section of infected untreated subgroup Ib showing marked infiltration of portal tracts by inflammatory cells (single arrow) and hydropic degeneration of hepatocytes (double arrows) (H\&E x200). c A liver section of infected untreated subgroup Ib showing fatty changes of hepatocytes (single arrow) and congestion of central veins (double arrows) (H\&E x200). d A liver section of infected control subgroup Ib showing T. gondii pseudocysts (H\&E x1000) e A liver section of the infected subgroup IIa treated with PYR $(5 \mathrm{mg} / \mathrm{kg})$ showing moderate infiltration of portal tracts by inflammatory cells (arrow) and marked congestion of central veins (double arrows) (H\&E x200). f A liver section of the infected subgroup Ilb treated with PYR (10mg/kg) showing moderate infiltration of portal tracts by lymphocytes (arrow) and moderate congestion of central veins (double arrows) (H\&E x200). g A liver section of the infected subgroup IIIa treated with PYR-niosomes $(5 \mathrm{mg} / \mathrm{kg})$ showing mild infiltration of portal tracts by lymphocytes (arrow) and mild congestion of the central vein (double arrows) (H\&E x200). h A liver section of the infected subgroup IIIb treated with PYR-niosomes (10mg/kg) showing infiltration of portal tracts by few lymphocytes (arrow) and minimal congestion of the central vein (double arrows) (H\&E x200).
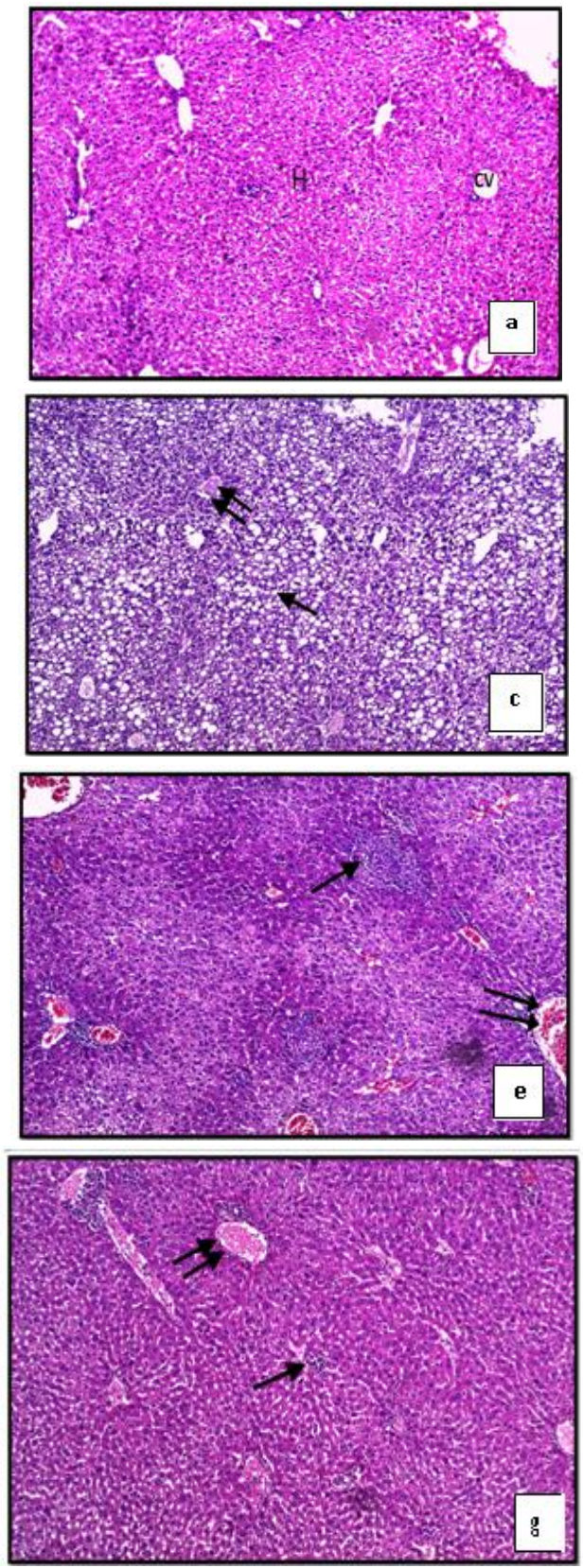
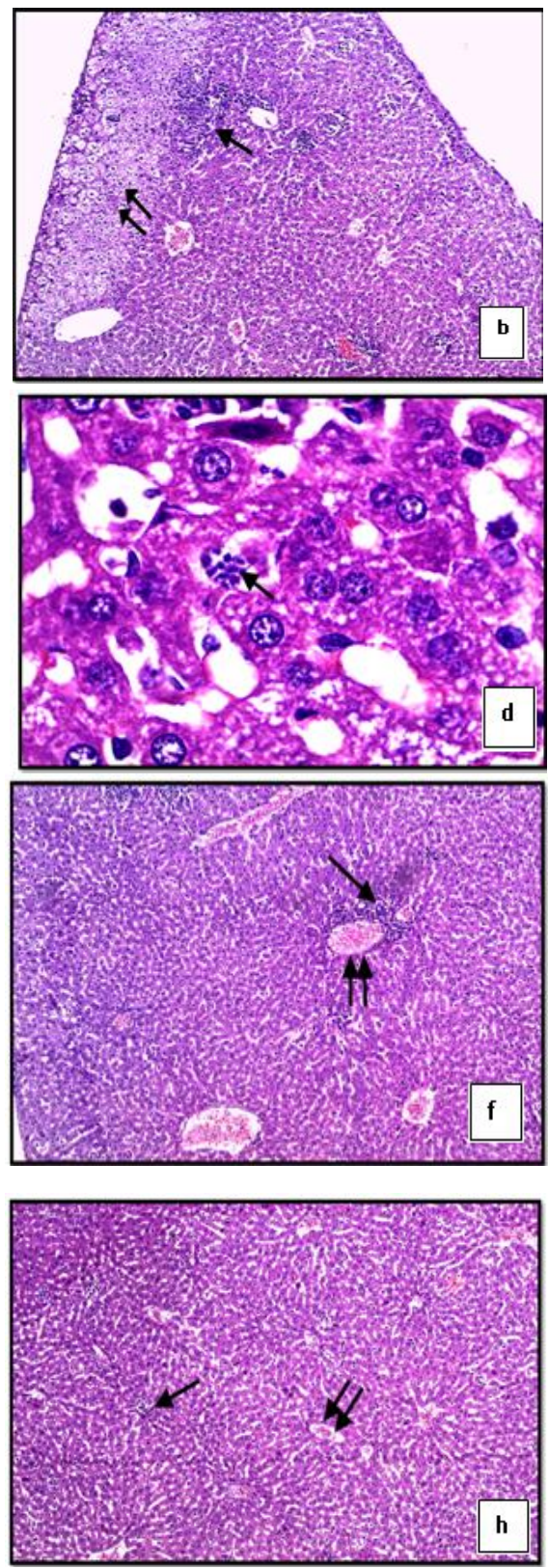
Fig.6 Spleen sections of the studied subgroups. a A spleen section of uninfected untreated control subgroup Ia showing normal lymphoid follicles (LF) (white pulp) and sinusoids (S) (red pulp) (H\&E x200). b A spleen section of infected untreated subgroup $\mathrm{Ib}$ showing hyperplastic lymphoid follicles, dilated congested sinusoids and infiltration of sinusoids by numerous mono and multinucleated giant cells (H\&E x200). c A spleen section of infected control subgroup Ib showing Toxoplasma pseudocysts containing tachyzoites (H\&E x1000). d A spleen section of infected subgroup IIa treated with PYR $(5 \mathrm{mg} / \mathrm{kg}$ ) showing hyperplastic lymphoid follicles (arrow) and dilated congested sinusoids infiltrated with many giant cells (double arrows) (H\&E x200). e A spleen section of infected subgroup IIb treated with PYR $(10 \mathrm{mg} / \mathrm{kg})$ showing hyperplastic lymphoid follicles (arrow) and dilated congested sinusoids infiltrated with few giant cells (double arrows) (H\&E x200). f A spleen section of infected subgroup IIIa treated with PYR-niosomes $(5 \mathrm{mg} / \mathrm{kg}$ ) showing reduced lymphoid follicles hyperplasia (arrow) and dilatation of the congested sinusoids infiltrated with few giant cells (double arrows)(H\&E x200). g A spleen section of infected subgroup IIIb treated with PYR-niosomes $(10 \mathrm{mg} / \mathrm{kg})$ showing reduced lymphoid follicles hyperplasia (arrow) and slightly congested sinusoids (double arrows) (H\&E x200).
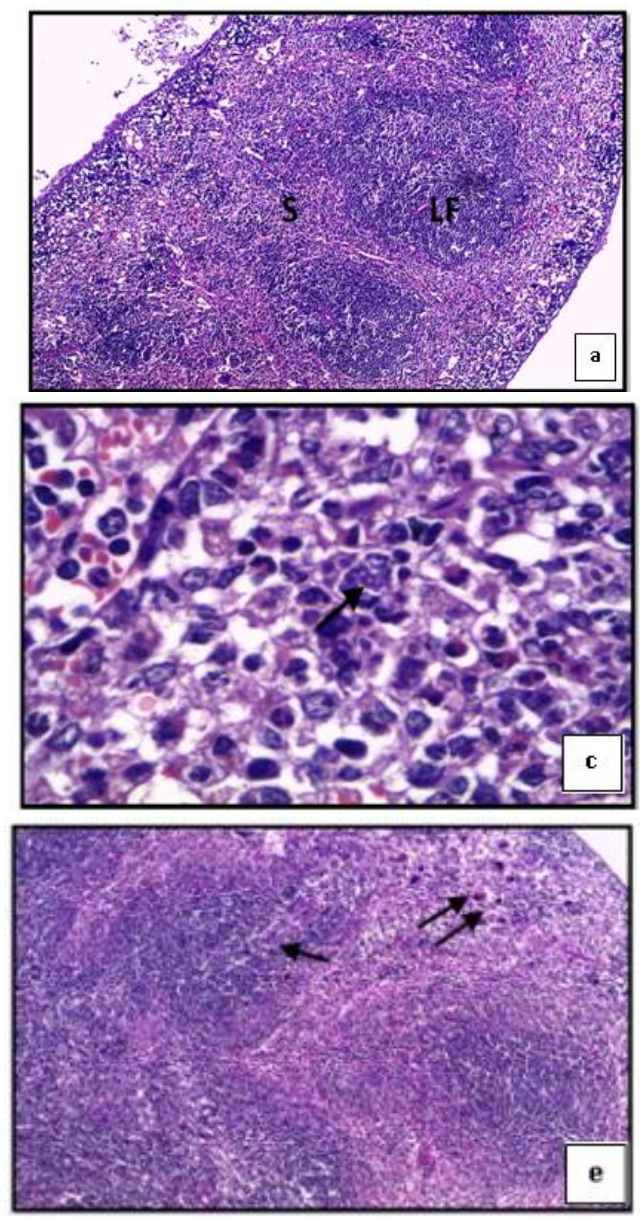
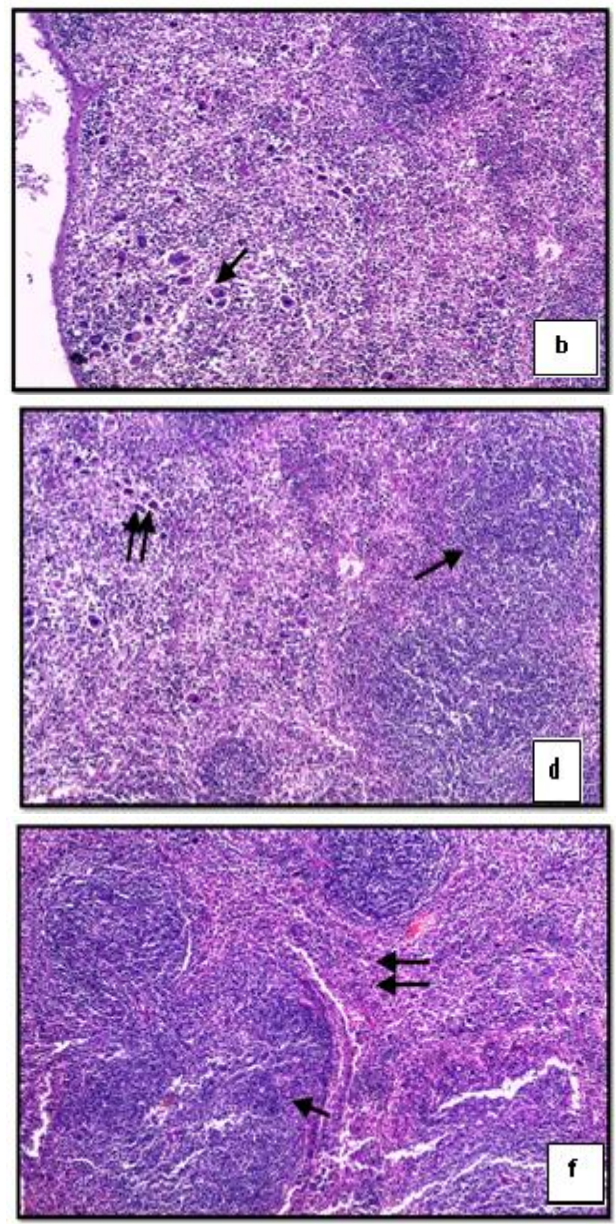

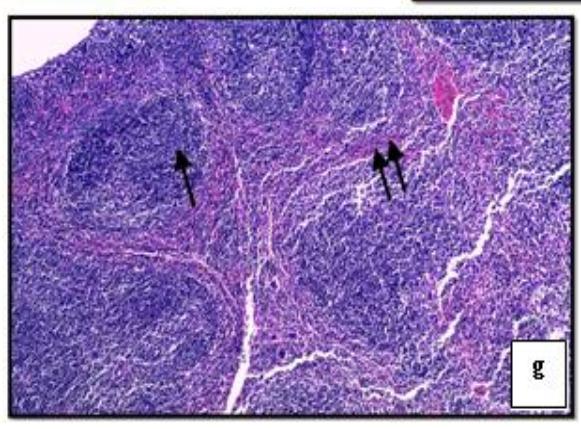


Fig.7 Brain sections of the studied subgroups a A brain section of the uninfected control subgroup Ia showing normal glial cells (arrow) and pyramidal neurons (double arrows) (H\&E $\mathrm{x} 100$ ). $\mathrm{b}$ A brain section of infected control subgroup Ib showing heavy inflammatory infiltrates and increased cellularity (H\&E x100). c A brain section of infected subgroup IIa treated with PYR $(5 \mathrm{mg} / \mathrm{kg})$ showing heavy inflammatory infiltration (H\&E x100). d A brain section of infected subgroup IIb treated with PYR $(10 \mathrm{mg} / \mathrm{kg})$ showing moderate inflammatory infiltration (H\&E x100). e A brain section of the infected subgroup IIIa treated with PYR-niosomes $(5 \mathrm{mg} / \mathrm{kg})$ showing mild inflammatory infiltration (H\&E x100). $\mathrm{f}$ A brain section of the infected subgroup IIIb treated with PYR-niosomes $(10 \mathrm{mg} / \mathrm{kg})$ showing infiltration of brain tissue by few inflammatory cells (H\&E x100).
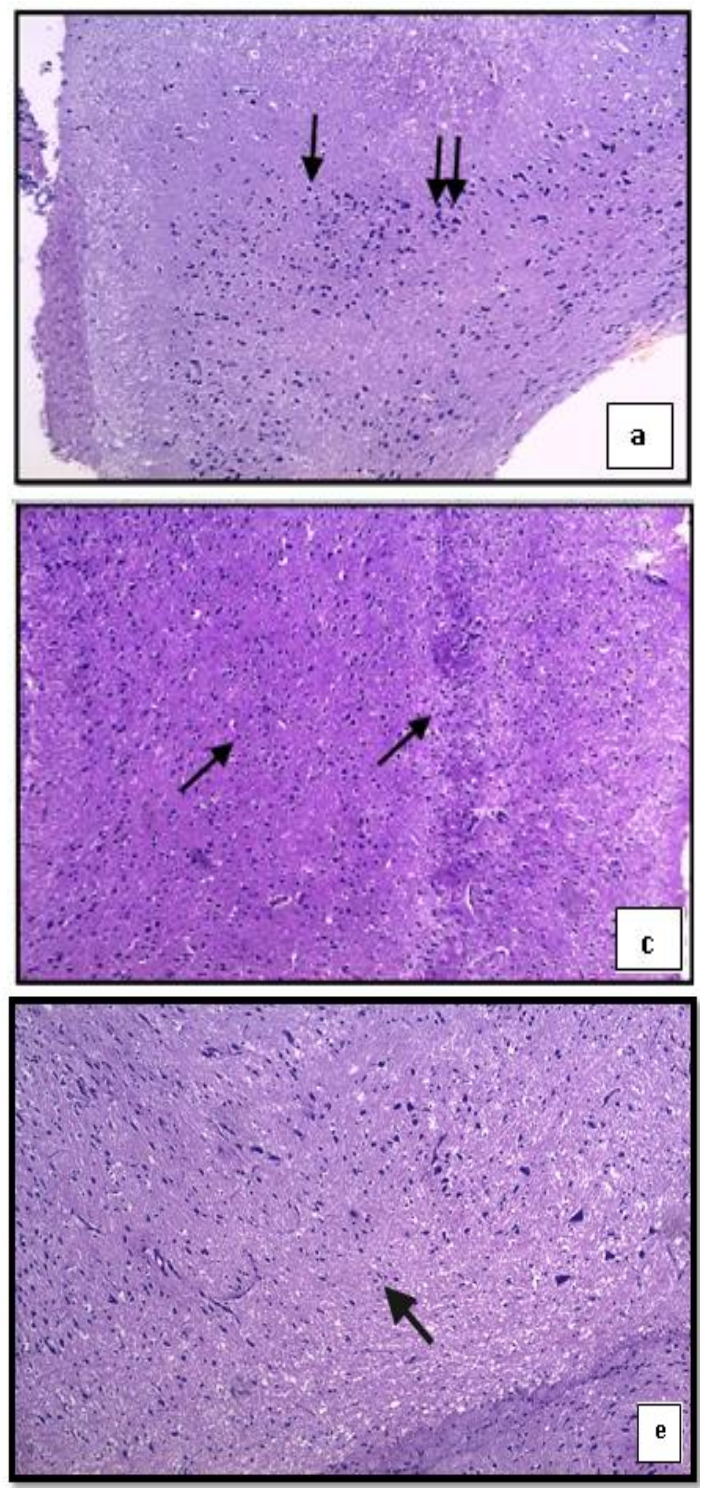
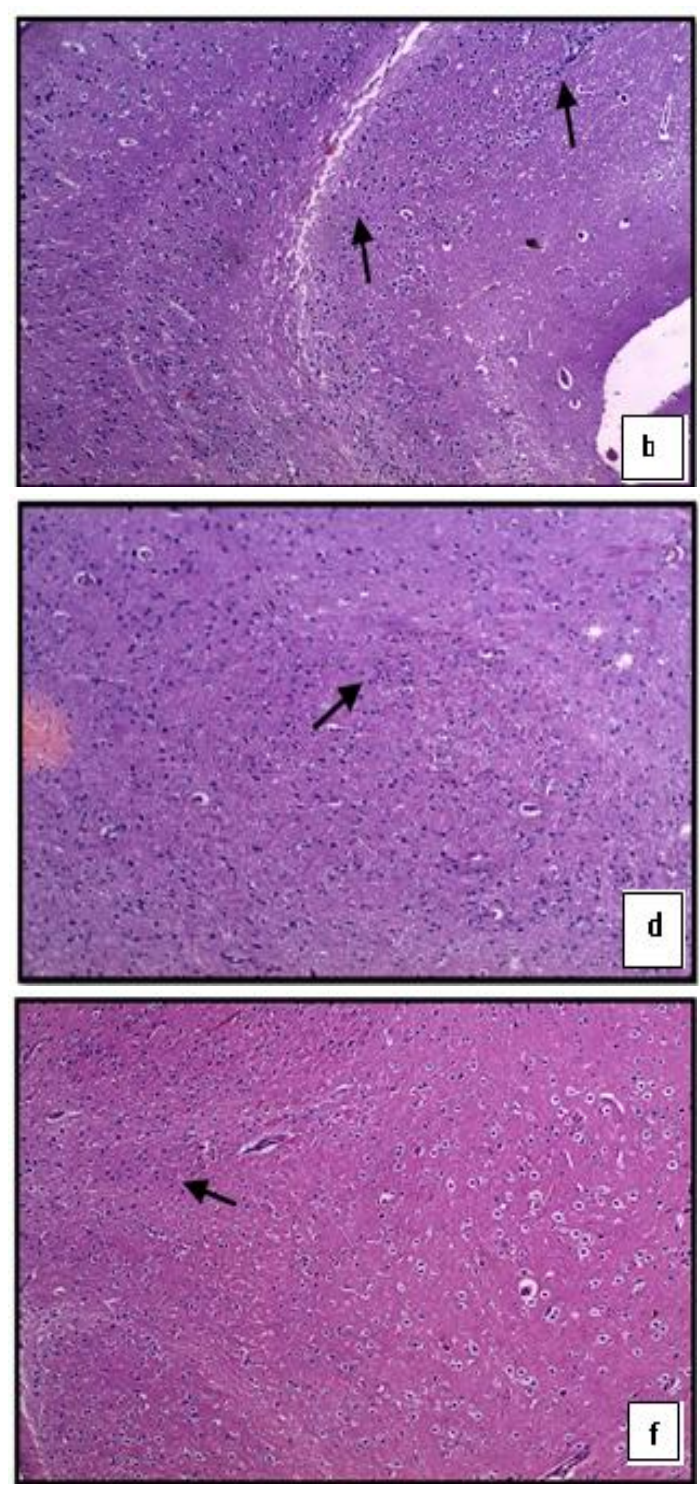
Concerning the morphological changes in the Toxoplasma tachyzoites in the peritoneal exudates of the studied subgroups, SEM showed severe deformities in the shape of the tachyzoites in group III as compared to group II in the form of large irregular ridges, deep furrows and disorganized conoids. These deformities may be referred to the interference of the drug with DNA synthesis of the parasite or interference with the folic acid cycle as suggested by Hammouda et al., (1992). Furthermore, the disorganized conoid of the tachyzoites is an indication of the antitoxoplasmic effect of the drug on the parasite, which prevents the entry of the organisms into the host cells and in turn causing the ultimate elimination of the parasite as explained by Aikawa et al., (1977). Similar morphological changes were reported by Gaafar et al., (2014) who compared chitosan and silver NPs with PYR in the treatment of acute toxoplasmosis in mice. Also Mady et al., (2016) reported the same results using PYR combined with Nigella sativa oil or clindamycin.

As regards the histopathological changes in the haematoxylin and eosin stained sections of the liver, spleen and brain of mice, there were heavy inflammatory infiltrates, congestion, areas of lytic necrosis and Toxoplasma tachyzoites within the tissue sections, in the infected control group. Similar changes were reported by Mady (2005), Mady et al., (2016) and El-Temsahy et al., (2016). In the subgroups treated with PYR-niosomes, there was a marked reduction of the inflammation in the all studied organs in the form of reduction of inflammatory infiltration, minimal congestion and absence of the tachyzoites within the tissues, while these changes were less evident in the subgroups treated with PYR alone with the same doses. This indicates that the PYR-niosomes are the most effective in controlling Toxoplasma infection and the subsequent inflammation. Similar results were reported by Anand et al., (2015) and Mady et al., (2016) after treating acute toxoplasmosis in mice by encapsulated bovine lactoferrin protein nanocapsules by the former authors and PYR combined with Nigella sativa oil (NSO) or clindamycin by the latter.

Concerning the biochemical results of the current study, there was no statistically significant increase in the serum levels of urea and the liver enzymes; aspartate aminotransferase (AST) and alanine aminotransferase (ALT) in the non infected subgroups Ic injected IP with the niosomes and subgroup Id injected IP with dimethyl sulfoxide (DMSO) as compared to the healthy non- infected untreated subgroup Ia. This indicates that the niosomes and DMSO have no toxic effects on the kidney or the liver of the mice. Similarly, El-Zawawy et al., (2015) found that there was statistically insignificant elevation of AST and ALT levels in the subgroup treated with triclosan liposomes as compared to the non-infected non-treated subgroup. Also these levels were lower than those in the subgroup treated with triclosan (TS) alone. The authors referred this to the ability of the liposomes to decrease the toxic effects of TS on the liver cells. Moreover, Pissinate et al., (2014) stated that there was an increase of urea and AST levels in the subgroup administrated IP with the lipid-core nanocapsules alone as compared to the untreated control subgroup. Whereas they found an unexpected decrease of ALT levels in the same subgroup and attributed that to the malnutrition of the mice.

In this work, niosomes loaded with pyrimethamine proved to be a powerful alternative to improve the efficacy and tolerability of this drug in the treatment of acute toxoplasmosis in mice. This was evidenced by the increased survival rate of the mice, the decreased tachyzoites count, the morphological changes by SEM and the decreased inflammation in tissues. The 
increased efficacy of PYR by the niosomes could be referred to many factors. The first depends on the colloidal nature of the niosomes that improves the PYR bioavailability or distribution to the mice tissues (Olivera et al., 2012). The second relies on the high ability of the niosomes to carry the drugs of low water solubility as PYR (Mourao et al., 2005).

The third can be attributed to the presence of peceol as one of noisome components. This material can fluidize the intestinal membrane with subsequent enhancement of bioavailability of the drug. The vesicular structure of niosomes was also linked with preferential lymphatic transport avoiding the pre-systemic metabolism and increased bioavailability (Sultan et al., 2016, 2018; Zoghroban et al., 2019). The ability of niosomes to fuse to the surface of the organisms as bacteria leading to entry of high concentrations of the carried drug into the organism has been suggested by Abdelaziz et al., (2015) and this may occur also in Toxolasma tachyzoites. These postulations can explain the superiority of niosomes over the unprocessed drug. Enhanced bioavailability after niosomal encapsulation can explain the recorded high efficacy of PYR-niosomes even at low dose with the recorded activity being greater than that recorded with higher dose of the free drug solution.

Niosomes-encapsulated pyrimethamine is more effective than PYR alone in the treatment of acute toxoplasmosis in mice. Moreover, the small dose of the niosomes loaded with PYR was more effective than the high dose of PYR alone in controlling the infection. So the use of PYR-niosomes formulation can reduce the PYR dose and consequently its side effects. Also niosomes loaded with pyrimethamine proved to be a safe alternative treatment that improves the tolerability of the drug in the treatment of acute toxoplasmosis in mice.

\section{Compliance with ethical standards}

Conflict of interest: The authors declare that there is no conflict of interest.

\section{References}

Abdelaziz AA, Elbanna TE, Sonbol FI, Gamaleldin NM, El Maghraby GM (2015) Optimization of niosomes for enhanced antibacterial activity and reduced bacterial resistance: in vitro and in vivo evaluation. Expert Opin Drug Deliv 12(2):163-80.

Aikawa M, Komata Y, Asai T, Midorkawa O (1977) Transmission and scanning electron microscopy of host cell entry by Toxoplasma gondii. Am J Pathol 87: 285-296.

Anand N, Sehgal R, Kanwar R K, Dubey ML, Vasishta R K, Kanwar J R (2015) Oral administration of encapsulated bovine lactoferrin protein nanocapsules against intracellular parasite Toxoplasma gondii. Int $\mathrm{J}$ Nanomedicine 10: 6355-6369.

Anderson AC (2005) Targeting DHFR in parasitic protozoa. Drug Discov Today 10:121-128.

Biswas AK, Islam MR et al., (2014) Nanotechnology based approaches in cancer therapeutics. Adv Nat Sci Nanosci Nanotechnol 5: 1-9.

Dhapte V, Kadam V, Pokharkar V (2013) Pyrimethamine nanosuspension with improved bioavailability: in vivo pharmacokinetic studies. Drug Deliv Transl Res 3(5): 416- 420.

Dunay IR, Heimesaat MM, Bushrab FN, Müller RH, Stocker H, Arasteh K, Kurowski M, Fitzner R, Borner K, Liesenfeld O (2004) Atovaquone maintenance therapy prevents 
reactivation of toxoplasmic encephalitis in a murine model of reactivated toxoplasmosis. Antimicrob Agents Chemother 48 (12): 48484854.

Eissa MM, El-Azzouni MZ, Mady RF, Fathy FM, Baddour NM (2012) Initial characterization of an autoclaved Toxoplasma vaccine in mice. Exp Parasitol 131(3): 310-316.

El-Temsahy MM, El-Kerdany ED, Abou Shama LM (2002) Study of the role of antioxidant in experimental toxoplasmosis. J Med Res Inst 23 (3): 59-69.

El-Temsahy MM, El Kerdany ED, Eissa MM, Shalaby TI, Talaat IM, Mogahed NM (2016) The effect of chitosan nanospheres on the immunogenicity of T. gondii lysate vaccine in mice. $\mathrm{J}$ Parasit Dis 40(3): 611-626.

El-Zawawy LA, ElSaid D, Mossallam SF, Ramadan HS, Younis SS (2015) Triclosan and Triclosan loaded liposomal nanoparticles in the treatment of acute experimental toxoplasmosis. Exp Parasitol 149:5464.

Gaafar MR, Mady RF, Diab RG and Shalaby ThI (2014) Chitosan and silver nanoparticles: Promising antiToxoplasma agents. Exp Parasitol 143:30-38.

Hakeen L (2010) The life cycle of toxoplasmosis, Ondokuz mayis university medical school Turkey, 50603 Kuala Lumpur, pp 412.

Hammouda NA, El-Mansoury ST, El-Azzouni MZ (1992) Toxoplasma gondii: scanning electron microscopic study before and after treatment. J Trop Med 2: 77-83.

Katlama C, De Wit S, O'Doherty E, Van Glabeke M, Clumeck N (1996) Pyrimethamine-clindamycin vs. pyrimethamine-sulfadiazine as acute and long-term therapy for toxoplasmic encephalitis in patients with AIDS. Clin Infect Dis 22(2): 268-75.

Klainer AS, Betsch CJ (1970) Scanning beam electron microscopy selected microorganisms. J Infect Dis 121: 339-343.

Leport C, Meulemans A, Robine D et al., (1992) Levels of pyrimethamine in serum and penetration into brain tissue in humans. AIDS 6:1040-1.

Leslie E, Geoffrey J, James M (1991) Statistical analysis. In: Interpretation and uses of medical statistics ( $4^{\text {th }}$ ed.). Oxford Scientific Publications P 411416.

Mady RF, El-Hadidy W, Elachy S (2016) Effect of Nigella sativa oil on experimental toxoplasmosis. Parasitol Res 115 (1): 379-390.

Mady RFM (2005) Efficacy of killed vaccine against experimental toxoplasmosis. MS Thesis, Faculty of Medicine, Alexandria University.

Mehta SK, Jindal N (2014) Tyloxapol niosomes as prospective drug delivery module for antiretroviral drug nevirapine. AAPS Pharm Sci Tech 16(1): 67-75.

Montoya JG, Boothroyd JC, Kovacs JA (2015): Toxoplasma gondii. In: Bennett JE, Dolin R, Blaser MJ (eds). Mandell, Douglas, and Bennett's Principle and Practice of Infectious Diseases, 8th edn, Philadelphia, PA, USA, Elsevier Saunders Inc, pp 312253.

Mordue DG, Monroy F, La Regina M, Dinarello CA, Sibley LD (2001) Acute toxoplasmosis leads to lethal overproduction of Th1 cytokines. J Immunol 167 (8): 4574-4584.

Mourao SC, Costa PI, Salgado H R, Gremiao MP (2005) Improvement of antischistosomal activity of praziquantel by incorporation into 
phosphatidyl choline-containing liposomes. Int J Pharm 295:157-162.

Munoz M, Liesenfeld O, Heimesaat MM (2011) Immunology of Toxoplasma gondii. Immunol Rev 240: 269-285.

Naseri N, Valizadeh H, Zakeri-Milani P (2015) Solid Lipid Nanoparticles and Nanostructured Lipid Carriers: Structure, Preparation and Application. Adv Pharm Bull 5(3): 305-313.

Oliveira CP, Venturini CG, Donida B, Poletto FS, Guterres SS, Pohlmann AR (2012) An algorithm to determine the mechanism of drug distribution in lipid-core nanocapsule formulations. Soft Matter 9: 1141-2012.

Pappas G, Roussos N, Falagas ME (2009) Toxoplasmosis snapshots: global status of Toxoplasma gondii seroprevalence and implications for pregnancy and congenital toxoplasmosis. Int $\mathbf{J}$ Parasitol 39 (12): 1385-94

Patravale VB, Date AA, Kulkarni RM (2004) Nanosuspensions: a promising drug delivery strategy. J Pharm Pharmacol 56:827-40.

Paul KB, Hedge JM, DeVito MJ, Crofton KM (2010) Short-term exposure to triclosan decreases thyroxine in vivo via upregulation of hepatic catabolism inyoung long-evans rats. Toxicol Sci 113 (2): 367-379.

Pissinate K, dos Santos Martins-Duarte É, Schaffazick SR (2014) Pyrimethamine-loaded lipid-core nanocapsules to improve drug efficacy for the treatment of toxoplasmosis. Parasitol Res (113): 555-564.

Pohlmann AR, Fonseca FN, Paese K, Detoni CB, Coradini K, Beck RCR, Guterres SS (2013) Poly (E-caprolactone) microcapsules and nanocapsules in drug delivery. Expert Opin Drug Deliv 10(5): 623-638.

Prieto MJ, Bacigalupe D, Pardini O, Amalvy JI, Venturini C, Morilla MJ, Romero
EL (2006) Nanomolar cationic dendrimeric sulfadiazine as potential antitoxoplasmic agent. Int J Pharmcol 326 (1-2): 160-168.

Rabinow BE (2004) Nanosuspensions in drug delivery. Nat Rev Drug Discov 3:78596.

Robert-Gangneux F， Dardé ML (2012) Epidemiology of and diagnostic strategies for toxoplasmosis. CMR 25(2): 264-296.

Saudi MN, Gaafar MR, El-Azzouni MZ, Ibrahim MA, Eissa MM (2008) Synthesis and evaluation of some pyrimidine analogs against toxoplasmosis. Med Chem Res 17: 541-563.

Schöler N, Krause K, Kayser O, Müller RH, Borner $\mathrm{K}$, Hahn $\mathrm{H}$, Liesenfeld $\mathrm{O}$ (2001) Atovaquone nanosuspensions show excellent therapeutic effect in a new murine model of reactivated toxoplasmosis. Antimicrob Agents Chemother 45 (6): 1771-1779.

Sharma S, Ramya T, Surolia A, Surolia N (2003) Triclosan as a systemic antibacterial agent in a mouse model of acute bacterial challenge. Antimicrob Agents Chemother 47 (12): 38593866.

Shubar HM, Dunay IR, Lachenmaier S, Dathe $\mathrm{M}$, Bushrab FN, Mauludin R et al., (2009) The role of apolipoprotein $\mathrm{E}$ in uptake of atovaquone into the brain in murine acute and reactivated toxoplasmosis. J Drug Target 17 (4): 257-267.

Shubar HM, Lachenmaier S, Heimesaat MM et al., (2011) SDS-coated atovaquone nanosuspensions show improved therapeutic efficacy against experimental acquired and reactivated toxoplasmosis by improving passage of gastrointestinal and blood-brain barriers. J Drug Target 19:114-124.

Sibley LD, Mordue DG, Su C, Robben DM, 
Howe DK (2002) Genetic approach to study virulence and pathogenesis in Toxoplasma gondii. Philos Trans R Soc Lond B 357:81-88.

Sordet F, Aumjaud Y, Fessi H, Derouin F (1998) Assessment of the activity of atovaquone loaded nanocapsules in the treatment of acute and chronic murine toxoplasmosis. Parasite 5: 223-9.

Sultan AA, El-Gizawy SA, Osman MA, El Maghraby GM (2018) Niosomes for oral delivery of nateglinide: in situ-in vivo correlation. J Liposome Res 2:19.

Sultan AA, El-Gizawy SA, Osman MA, El Maghraby GM (2016) Colloidal carriers for extended absorption window of furosemide. $\mathrm{J}$ Pharm
Pharmacol 68(3): 324-32.

Sultan AA, El-Gizawy SA, Osman MA, El Maghraby GM (2017) Peceosomes for oral delivery of glibenclamide : In vitro in situ correlation. J drug deliv Sci Tech 41: 303-309.

Thiptara A, Kongkaew W, Bilmad U, Bhumibhamon T, Anan S (2006) Toxoplasmosis in piglets. Ann NY Acad Sci 1081: 336-338.

Zoghroban HS, El-Kowrany SI, Aboul Asaad IA, El-Nouby KA, El Maghraby GM, Abd Elazeem MA (2019) Niosomes for enhanced activity of praziquantel against Schistosoma mansoni: in vivo and in vitro evaluation. Parasitol Res 118: 219-234.

\section{How to cite this article:}

Basma M. El-Mansory, Samy I. El-Kowrany, Sirria M. El-Marhoumy, Kholoud A. El-Nouby, Mona A. Abd Elazeem and Gamal M. El Maghraby. 2019. An Experimental Study on the Effect of Pyrimethamine-Loaded Niosomes in the Treatment of Acute Toxoplasmosis. Int.J.Curr.Microbiol.App.Sci. 8(12): 542-561. doi: https://doi.org/10.20546/ijcmas.2019.812.072 